\title{
Teaching Materials for MSE Education
}

The Materials Education Council is the international materials science and engineering community's self-help program in preparing and distributing educational materials. The following is a description of the rationale, development, and present status of this agency.

\section{Rationale}

In 1974, a group of materials science and engineering (MSE) educators saw three primary forces which were creating a dangerous gap in the specialized, applied science educational system, primarily because of a shortage of instructional materials. In order of impact, they identified these forces as:

1. The declining publication of textbooks (down nearly 50\% in 3-4 years) in all the smaller fields of science and technology, including MSE, due to decreasing cost effectiveness to publishers;

2. The heterogeneous backgrounds of learners; and

3. The accelerating increase in scientific knowledge plus the appearance of entire new subsets of knowledge across the diverse subfields of MSE.

Use of the most effective and up-to-date instructional materials is a keystone in the educational process. Providing such materials is the most reliable way to ensure that the desired content is, in fact, imparted. It is at this point that new technologies can enter the system and improve its cost effectiveness and content. Furthermore, controlling the content of the new material is a subtle way of shaping a curriculum change.

\section{Historical Background}

The National Science Foundation (NSF) recognized that the production of new instructional materials was a key to content improvement and curriculum modernization. In the early/mid 1970s, the NSF provided $\$ 30-40$ million (current dollars) over a ten-year period for the establishment of national consortia in many of the disciplines: mathematics, chemical engineering, physics, materials science, digital systems, etc. Since these projects were not all started at the same time, they are in various stages of development, several having ceased with the termination of funding. However, some of the mature consortia have not only completed their system development but have produced modular print materials as well. For at least four of these consortia, the concept has become reality; their products include hundreds of educational modules, two journals for distributing the modules, funded national and international workshops for module production, computer programs for the selection of learning paths, and more.
None of these projects were involved in the 1981 controversy regarding the NSF Directorate of Science Education; however, when the directorate was eliminated by the Office of Management and Budget, all the projects suddenly lost their main source of support. College-education support has not yet reappeared in the NSF. The Materials Education Council (formerly the Educational Modules for Materials Science and Engineering Project) was one of the most developed of the consortia. The NSF had funded this project through two and onehalf phases over about eight years.

The first phase of the project involved development of the concept and the system. During this time, one of the most critical tasks undertaken was to develop a constituency and to raise their level of consciousness. MSE was a new subset or prototype discipline drawing from many classical disciplines such as chemistry, physics, electrical engineering, the geosciences, ceramic science and engineering, metallurgy, and others. A national "Depth Committee," consisting of the heads of existing materials science and engineering departments, was only a starting place for community development. The attempt was made to socialize all materials-related college and university departments, professional societies, and industries. Continuing support demonstrates the Council's success in this area, although community socialization is an ongoing task.

Another of the project's early, critical tasks was the development of prototype modules. This was necessary in order that the MSE community, as well as prospective authors, could understand just what a module is. Several different styles were developed: formats ranged from highly pedagogical, one-lecture/study packages to programmed learning and to reprinted out-of-print but highly significant books. Rigid formatting did not survive, but a loosely structured, pedagogically sound style did emerge, one that is more or less comparable with those of other major consortia.

The production of modules is only half the game; getting the modules into the hands of users is equally important. The council recognized, largely from observing other learning aids projects, that many fine materials are not used beyond a small fraction of their potential. The second phase saw the emergence of a journal-text hybrid, the bimonthly Journal of Materials Education (JME), as a major innovation in the mode of module distribution. Institutional subscription to $J M E$ confers unlimited copying rights. This facilitates on-site, on-demand printing and eliminates the problems of warehousing and mailing modules, thus saving a major portion of the cost of printed materials. Faculty and students simply copy what they need, selecting a "best set" of modules on a particular topic from back issues.

Because most scientists and engineers in the United States, at least in MSE, are too busy to write educational modules, another

Continued

\section{CALL FOR PARTICIPATION \\ JME Invites \\ Manuscripts, Computer Programs, and Videotapes Made for Education}

The Journal of Materials Education Editorial Board invites all Materials Research Society members from industry, government, or university who have developed any new material for teaching or training to submit them for appropriate publication/distribution.

All JME materials may be reproduced free on site for use by students. Authors contribute their materials for the benefit of the entire community.

JME Editorial Board:
C. Wert
R. Roy
R. Davis
S. Carr
C. Hartley
B.E. Knox
W. Brostow
L.H. Van Vlack

Submit materials to: 
mechanism had to be found to encourage the original preparation of modules for $J M E$. Module preparation workshops, pioneered by the "wood" scientists at the USDA Forest Products Laboratory and further developed by our West European Coordinating Committee in a series of ongoing NATO Workshops, proved to be an excellent source of peer-reviewed materials for publication. Another source is review papers presented at scientific meetings, such as the Symposium $X$ series on Frontiers of Materials Research at Materials Research Society meetings. Individual authors (solicited or unsolicited) provide the remainder of the modules printed in the Journal.

\section{Current Status}

The Materials Education Council is now a self-supporting not-for-profit organization, generating income from sales of the Journal of Materials Education and topical "clusters" or sets of modules in book form. (The four main sets are crystallography, polymer lab experiments, a complete series on wood as a material, and cement science.) Nearly 10,000 of these are sold every year. The $J M E$ is currently being translated into Japanese for distribution in Japan. Another module-writing workshop is being planned in Europe (with EEC funding) late in 1987. The JME Editorial Board welcomes submission of module manuscripts from the MRS membership. A new arrangement for co-publishing selected review articles with the MRS BULLETIN is in place.

The Council has recently embarked upon a plan to acquire and/or produce a library of instructional video tapes in MSE, ultimately to act as a source/clearinghouse for the teaching aids. Cooperation with several professional societies in MSE has been established, and all Materials Education Council publications are made available to their members at substantial savings.

RUSTUM ROY

Evan Hugh Professor of the Solid State ROBERT BERRETTINI

Research Associate, Materials Research Lab The Pennsylvania State University

\title{
Frontiers in Materials Education
}

\author{
Edited by L.W. Hobbs and G.L. Liedl
}

The explosion of growth in electronic materials, polymers, ceramics, composites and other materials provides a challenge to Materials Science and Engineering educators. What is "materials science"? Which is better-single-discipline or multi-discipline majors? How can universities better prepare students for careers in industry?

Frontiers in Materials Education contains 15 papers by leading materials educators presented at a symposium conducted at the 1985 MRS Fall Meeting, which address these issues and more:

- Approaches to an integrated undergraduate education in materials science and engineering

- The metals/materials dichotomy: real or apparent

- Pedagogical theories and strategies in education for materials research: a hierarchical approach

- Ceramic engineering education

- University-industry interactions-education from entrepreneurship

- Materials education and the national laboratories

- Recruitment and retention of lower division metallurgy/materials students

The book provides a wealth of information and insight into Materials Science and Engineering education at Massachusetts Institute of Technology, Carnegie Mellon University, Pennsylvania State University, Ohio State University, Wayne State University, University of Texas at El Paso, Clemson University, The Open University (UK), Johns Hopkins University, Case Western Reserve University, Alfred University, SUNYBuffalo, University of Lowell, and Drexel University.

The collection of papers provides both historical perspective on materials education and modern teaching trends. Samples of various curriculae are also included.

MRS Members: $\$ 29.00 \quad$ U.S. List: $\$ 36.00 \quad$ Foreign List: $\$ 43.00$

FRONTIERS IN MATERIALS EDUCATION

Volume 66 of MRS Symposia Proceedings Series-hardbound, illustrated, 156 pages ISBN 0-931837-31-6

Order from Publications Department, Materials Research Society, 9800 McKnight Road, Suite 327, Pittsburgh, PA 15237; telephone (412) 367-3012.

Prepayment required. MasterCard, VISA, Diners Club accepted. 